\title{
Characterization and evaluation of the variability of dragon fruit accessions in Dairi District, North Sumatra Province, Indonesia
}

\author{
LUTHFI AZIZ MAHMUD SIREGAR ${ }^{\bullet}$, NINA UNZILA ANGKAT, REVANDY ISKANDAR DAMANIK \\ Department of Agro-technology, Faculty of Agriculture, Universitas Sumatra Utara. Jl. Prof A. Sofyan No. 3 Padang Bulan, Medan 20155, North \\ Sumatra, Indonesia. Tel./fax. +62-61-8213236, `email: luthfi1@usu.ac.id
}

Manuscript received: 31 January 2021. Revision accepted: 31 May 2021.

\begin{abstract}
Siregar LAM, Angkat NU, Damanik RI. 2021. Characterization and evaluation of the variability of dragon fruit accessions in Dairi District, North Sumatra Province, Indonesia. Nusantara Bioscience 13: 138-145. Many types of dragon fruits were planted in Dairi District of North Sumatra Province without much information of their importance in economic values. Therefore, this study was carried out to evaluate the variability of the dragon fruit population in this region to assist the local farmers in selecting the best species for planting. This study used a morphological observation method based on dragon fruit descriptor employing a purposive sampling technique. A total of 56 dragon fruit accessions collected from Sidikalang, Sitinjo, and Siempat Nempuhulu Sub-districts were studied and characterized based on the morphological characteristics of stems, flowers, and fruit. The results showed some variations in the stem, flower, and fruit morphology among the studied population. The dragon fruit plant that is widely cultivated by farmers in three sub-districts of Dairi District is a species of Hylocereus polyrhizus. Phenotypic diversity analysis showed seven quantitative characters with broad criteria of eighteen characters observed, namely stem length, pericarpel length, number of lobes, flower shoot length, number of bractea, bractea peak length, and fruit weight. However, phenotypic diversity analysis indicates they are closely related to each other except for accession D17 the red dragon fruit or red pitaya (Hylocereus spp.), and it could be the exotic species for nation-wide planting in Indonesia.
\end{abstract}

Keywords: accession, Dairi District, dragon fruit, morphological characteristic, phylogenetic

\section{INTRODUCTION}

Dragon fruit (Hylocereus spp.), also known as pitaya or pitahaya, belongs to the Cactaceae family. The genus Hylocereus recently was included in Selenicereus group (Korotkova, et al. 2017). The plant is native to Central America and it was spread from Florida to Brazil. There are about 14 major Hylocereus species in America but the popularly cultivated worldwide species are Hylocereus undatus, H. monachantus, and H. megalanthus (Hernandez and Salazar 2012).

Dragon fruit plants were introduced into Indonesia around year 2000 from Thailand. They were later cultivated as an agricultural crop in some areas such as Yogyakarta, Malang, Mojokerto, Bogor, and Jember (Purba 2012). At this time, dragon fruit has been widely known in various regions of Indonesia. Initially, this fruit was difficult to find in traditional markets and could only be found in certain supermarkets, but with the increasing area and spread of planting areas, dragon in fruit marketing has spread to various circles of society including in traditional markets. However, it is still a relatively new crop, hence the dragon fruit in Indonesia still has a low diversity (Santoso 2013; Winarsih 2010). Until now, the cultivation of dragon fruit in Indonesia is still concentrated in a few areas such as the islands of Java, Sumatera, and Kalimantan.

There are two peel types of dragon fruits that have been released in Indonesia. They are the white flesh and the red flesh dragon fruits (Kristanto 2008). Phenotypic and genotypic characterization of dragon fruits would be useful for the dragon fruit plant breeding program. However, the characterization based on morphological and cytological characters is still limited for the dragon fruits until today. The availability of this information would be of great assistance in developing an appropriate method for the cultivation of a particular species (Setyowati 2008). Studies have found that high variation in characteristics of agronomic importance, even within the same species of Hylocereus is considered valuable for future breeding studies (Tran and Yen 2014).

Several studies related to the diversity of dragon fruit have been reported. Rahmawati and Mahajoeno (2009) reported a study of variations of dragon fruit based on morphology, isozyme, and vitamin $\mathrm{C}$ content in the area of Pasuruan (East Java), Sukoharjo, and Klaten (Central Java), and Bantul sub-districts (Yogyakarta). Tran and Yen (2014) reported a study on pollination methods on fruit set and fruit characters in several Pitaya clones, which aimed to improve pollination efficiency, fruit quality, and yield by determining pollination agro-management requirements.

Cultivation of dragon fruits has been undertaken in Dairi District, North Sumatra, for more than five years but on a small scale. Due to the lack of information on the origin and scientific information about the genotypes cultivated, this research was conducted to study the morphological and related characters of dragon fruit in the highlands of Dairi District, North Sumatra. This study can 
be an initial reference and source of germplasm to carry out further studies in the field of plant breeding utilizing genotypes or accessions of dragon fruit cultivated in North Sumatra.

\section{MATERIALS AND METHODS}

This study was conducted from April to June 2017 at the dragon fruit farms in the Sitinjo, Sidikalang, and Siempat Nempuhulu Sub-districts in Dairi District of North Sumatra.

The research location was determined by first obtaining information on the number of dragon fruit farmers through the local government in 3 sub-districts in Dairi District, North Sumatra, namely Sidikalang Subdistrict, Sitinjo Sub-district, and Siempat Nempuhulu Subdistrict. Based on this information, 14 farmers have been practicing dragon fruit cultivation for more than three years. For every one farmer's land, 4 (four) plant accessions were taken as sample plants, therefore 56 (fifty-six) sample plants were obtained which were used in this study. The study samples used were healthy disease-free dragon fruits at flowering and fruiting stages. A purposive sampling method was used on accessions in each study area. Data collection was conducted by observing morphological characters qualitatively and quantitatively (Table 1) based descriptor guidebook International Union for The Protection of New Varieties of Plant (UPOV) for dragon fruit plants.

The qualitative and quantitative data were standardized and the phylogenetic was analyzed by using IBM SPSS program (Statistical Package for the Social Sciences) version 21 with cluster analysis to determine the degree of relationship between the accession of each sample. Cluster analysis was used to visualize the multivariant data (of the measured parameter) survey. Cluster analysis resulted in a dendrogram used to assess patterns of diversity of the survey data. Agglomerative Hierarchical Clustering with average linkage (between-group) method was used according to Mongi (2015) as stated below.

$$
\mathrm{di}_{y} \mathrm{j}=\sqrt{\sum_{\mathrm{k}=1}^{\mathrm{p}}\left(\mathrm{x}_{\mathrm{ik}}-\mathrm{x}_{\mathrm{jk}}\right)^{2}} \text { with: }
$$

Where:

$\mathrm{di}, \mathrm{j}$ : the distance between the object $\mathrm{i}$ with the object $\mathrm{k}$

xik : object value $\mathrm{i}$ at the variable to-k

$\mathrm{xjk}$ : object value $\mathrm{j}$ at the variable to-k

$\mathrm{p}$ : number of variables cluster

In addition, the phenotypic diversity value was calculated according to the following equation (Steel et al. 1997):

$$
\sigma^{2} \mathrm{p}=\frac{\sum\left(\mathrm{x}_{\mathrm{i}}-\mathrm{x}\right)^{2}}{\mathrm{~N}}
$$

Where: $\sigma{ }^{2} p$ is the diversity of phenotypes, $x_{i}$ is the sample values of $-\mathrm{i}$, and $\mathrm{x}$ is the value of the sample average of $-\mathrm{i}$.

The standard deviation of phenotypic diversity was calculated as:

$$
S d \sigma^{2} p=\sqrt{\sigma^{2} p}
$$

$S d \sigma^{2} p$ is the standard deviation of phenotypic diversity

The criteria for assessing the breadth and depth of phenotypic diversity are determined based on the following conditions (Mansyah et al. 2003):

- If $\sigma^{2} p>2 S d \sigma^{2} p$, it means that the diversity is wide.

\begin{tabular}{|c|c|c|c|}
\hline \multirow{2}{*}{ Organ } & \multicolumn{3}{|c|}{ Characters } \\
\hline & Qualitative & \multicolumn{2}{|c|}{ Quantitative } \\
\hline Stem & $\begin{array}{l}\text { Stem surface texture } \\
\text { Color of thorns } \\
\text { Bone edges shape } \\
\text { The intensity of gray on areoles }\end{array}$ & $\begin{array}{l}\text { Stem length }(\mathrm{cm}) \\
\text { Stem width }(\mathrm{cm}) \\
\text { Distance between areoles }(\mathrm{cm} \\
\text { Arch height }(\mathrm{mm}) \\
\text { Long thorns }(\mathrm{mm})\end{array}$ & \\
\hline Flower & $\begin{array}{l}\text { Flower bud shape } \\
\text { Flower bud shape of the apex } \\
\text { Flower bud color } \\
\text { The intensity of red color of bract } \\
\text { Sepal main color } \\
\text { Sepal: pattern of secondary color } \\
\text { Cleavage of the pistil lobe } \\
\text { Color of stigma lobes }\end{array}$ & $\begin{array}{l}\text { Flower bud: length of the peri } \\
\text { Flower bud: width of the peric } \\
\text { Flower bud: length of the peri } \\
\text { Length of style }(\mathrm{cm}) \\
\text { Number of stigma lobes }\end{array}$ & \\
\hline Fruit & $\begin{array}{l}\text { Position of bracts towards the peel } \\
\text { The main color of middle bracts } \\
\text { Color of peel (exclude bracts) } \\
\text { Color of flesh }\end{array}$ & $\begin{array}{l}\text { Fruit length }(\mathrm{cm}) \\
\text { Fruit width }(\mathrm{cm}) \\
\text { Fruit: ratio length/width } \\
\text { Fruit: number of bracts } \\
\text { Length apical of bracts }(\mathrm{cm})\end{array}$ & $\begin{array}{l}\text { Width of the base of the bracts } \\
(\mathrm{cm}) \\
\text { Thickness of peel }(\mathrm{mm}) \\
\text { Sweetness } \\
\text { Fruit weight }(\mathrm{g})\end{array}$ \\
\hline
\end{tabular}

- If $\sigma^{2} p>2 S d \sigma^{2} p$, it means that the diversity is narrow.

Tabel 1. The qualitative and quantitative characters of dragon fruit observed in this study 


\section{RESULTS AND DISCUSSIONS}

\section{Morphological diversity of dragon fruits in Dairi District}

Results obtained from the 56 accessions of dragon fruit planted from three sub-districts in Dairi District, North Sumatra showed that there were differences in several morphological characters of stems, fruits, and buds. However, there were also similarities in terms of flower crown color, lobe color, and spine color among the study's accessions.

The stem morphology used for the characterization study was stem length, stem width, arch height, the texture of the stem surface, and the shape of the bone edges of the stem (Figure 1). Most of the dragon fruit plants have a triangular stem with smooth surface textures. Some stem is rectangular in shapes such as G1 and G19, while some have a rough texture like those in G3. In addition, the character of the bone edges found is convex, but in G17 accession is flat.

According to plantation owners, the G1 accession is an unknown variety, while G19 accession is the Super-red hybrid variety. According to Rahmawati and Mahadjoeno
(2009), the dragon fruit plants planted in Pasuruan, Sukaharjo and Bantul have significant differences in stem morphology between the different species/varieties. The variations in stem morphology such as curvature of the stem, margin hardness (presence of sclerenchyma), distance between areoles, number of spines, rib height, rib thickness, length, color of the stem, and are considered important for species differentiation (Mejia et al. 2013).

The results of descriptive observations on the morphology of flowers showed that the length of the pericarpel, the length of the flower shoots, the length of the stigma, and the number of lobes were different in some of the observed accessions. Floral morphology such as flower bud shape, the color of flower bud, and petal pattern were found to be different in several accessions. The flower buds of dragon fruit plants are generally oval in shape (narrow ellipse and medium ellipse), but accessions G1, G11, G38, G43, G48, G49, G50, G52, and G53 have intense red round flower buds. All have similar white flower crowns. However, the pattern of flower petals found is a pattern of petals on the edge and has no pattern (Figure 2).

Length of stem segment

\section{Width of stem and} arch height

Stem surface texture

Bone edge shape

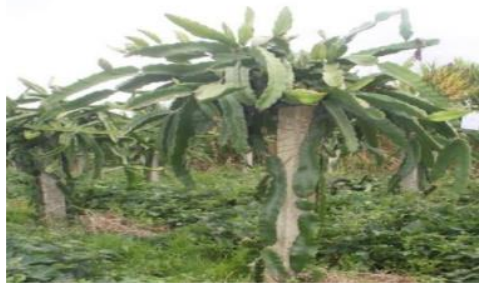

G44 accession,

short stem length

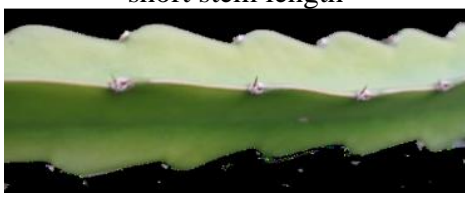

G41 accession, small trunk width with high arch height

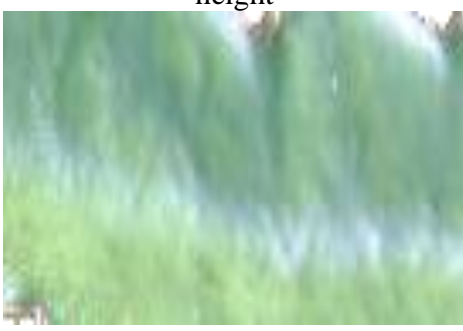

G3 accession, rough

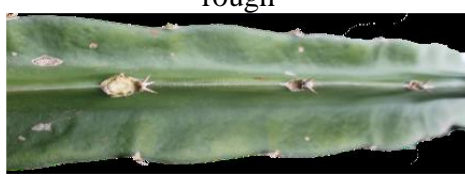

G17 accession,

Flat

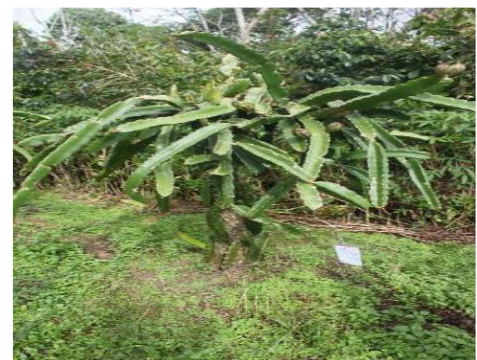

G51 accession, medium stem length

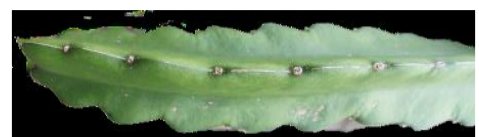

G29 accession,

medium stem width with medium arch height

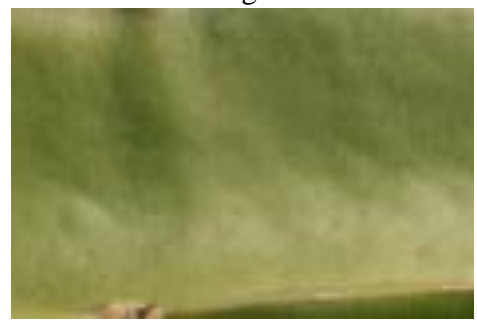

G33 accession, medium

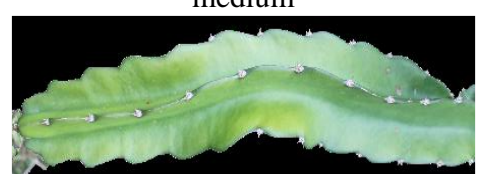

G33 accession, convex

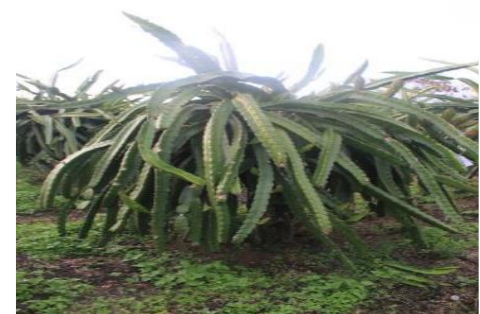

G56 accession, long stem length

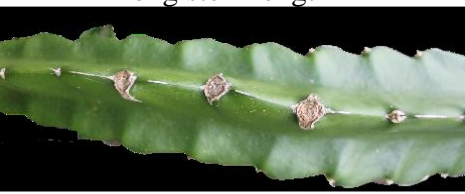

G26 accession,

large trunk width with small arch

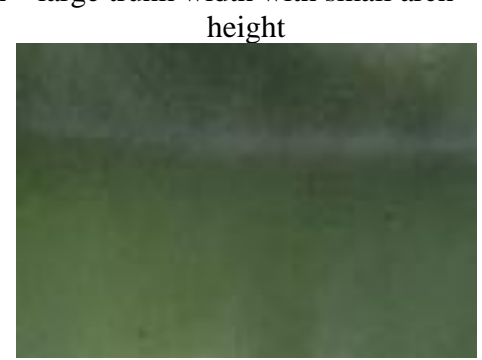

G35 accession, smooth

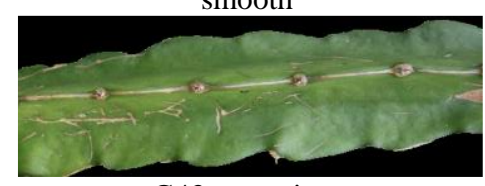

G43 accession, convex

Figure 1. The morphological characters of the stems showing a variety of phenotypes 
Flower bud shape

Bud flower color

Petal pattern plants showing broad phenotype diversity in Dairi Sub-district, North Sumatra Province

\begin{tabular}{lccccc}
\hline & \multicolumn{5}{c}{ Morphological of stem characteristic } \\
\cline { 2 - 6 } Value & $\begin{array}{c}\text { Length of } \\
\text { stem } \\
\text { segment } \\
(\mathbf{c m})\end{array}$ & $\begin{array}{c}\text { Width of } \\
\text { stem } \\
(\mathbf{c m})\end{array}$ & $\begin{array}{c}\text { Arch } \\
\text { height } \\
(\mathbf{m m})\end{array}$ & $\begin{array}{c}\text { Distance } \\
\text { between } \\
\text { areoles } \\
(\mathbf{c m})\end{array}$ & $\begin{array}{c}\text { Length } \\
\text { of spine } \\
(\mathbf{m m})\end{array}$ \\
\hline$\overline{\boldsymbol{X}}$ & 81.75 & 6.24 & 4.76 & 4.59 & 3.14 \\
$\boldsymbol{\sigma}^{\mathbf{2}} \mathbf{p}$ & 1243.8 & 1.85 & 2.39 & 0.96 & 0.91 \\
$\mathbf{S d ~}^{\mathbf{2}} \mathbf{p}$ & 35.2 & 1.36 & 1.54 & 0.98 & 0.95 \\
$\mathbf{2 S d} \boldsymbol{\sigma}^{\mathbf{2}} \mathbf{p}$ & 70.4 & 2.72 & 3.09 & 1.96 & 1,90 \\
Criteria & Broad & Narrow & Narrow & Narrow & Narrow \\
\hline
\end{tabular}

Note: $\overline{\boldsymbol{X}}$ : mean value; $\boldsymbol{\sigma}^{2} \mathrm{p}$ : diversity of phenotypes; $\mathrm{Sd} \sigma^{2} \mathrm{p}$ is standard deviation of phenotypic diversity

Castillo et al. (2005) found that the major differences between accessions were presented in the characteristics of reproductive structures. Tran and Yen (2014) reported that three similarities in all clones were confirmed, including the spherical button shape of the medium elliptical, the petal color of white, and the stigma lobe color of cream. In part, the differences were recorded at the dimension of mature bud and part structures of flowers.

The fruit morphology in dragon fruit is important for characterization study to differentiate one species from another. It was found that dragon fruits in Dairi District have different fruit morphological in terms of fruit shape, number of bractea, and the position of bractea. The shape of the fruit could be categorized as medium (as in G9), elongated (as in G13), and compressed (as in G41). The

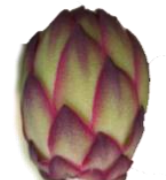

G4 accession, medium elliptical bud

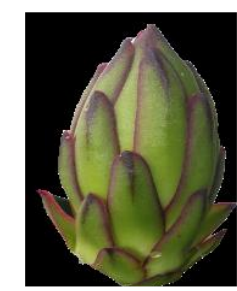

G24 accession, red color

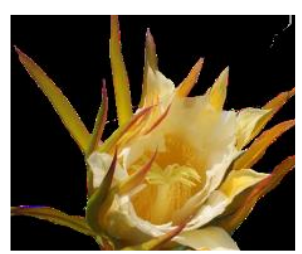

G16 accession, there is no pattern yellowish-green with a weak

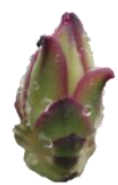

G12 accession,

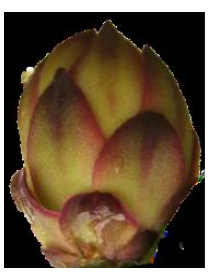

G31 accession, greenish-yellow with a medium red color

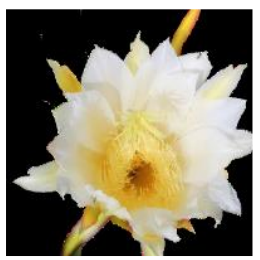

G12 accession, there is no pattern narrow elliptical bud

number of bractea correlates with the base width of the bractea, where dragon fruit with a large number of bractea has a narrow base width. The position of the bractea that was found was upright and attached (adpressed) (as in G20), slightly held out (as in G6), and strongly held out (as in G22) (Figure 3).

Based on the character of pink to red flesh color and red fruit skin, it can be concluded that the dragon fruit that farmers in Dairi District widely cultivate is a species of $H$. polyrhizus. Sudarjat et al. (2019) reported that four dragon fruit accessions have different characterizations, including growth and the ability to adapt to certain environments. There are three types of dragon fruit: Hylocereus undatus, pink skin with white flesh; $H$. polyrhizus, red flesh with pink skin; $H$. costaricencis, violet red flesh with pink skin and Hylocereus (Selenicerus) megalanthus, white flesh with yellow skin (Le Bellec et al. 2006). Fruit set, fruit weight, and total soluble solid content of four pitaya clones were differently influenced by pollination types (Tran and Yen 2014).

\section{Phenotype diversity}

Based on the analysis of phenotypic diversity by comparing the standard deviation values, it can be seen that in the morphological characterization of the stem there are (one character with broad phenotypic diversity criteria, namely length of the stem, and four narrow phenotypic diversity, namely width of stem, arches high, the distance between areoles and the length of the spines (Table 1). According to De Dios (2005), most species of Hylocereus were similar in stem and flower morphology. 
Length/width ratio

Bractea position

The color of the flesh

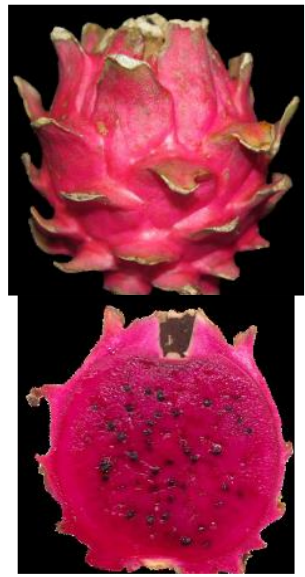

G13 accession, Moderately elongated

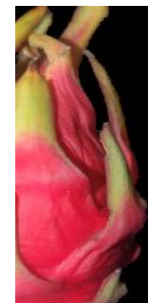

G20 accession, adpressed

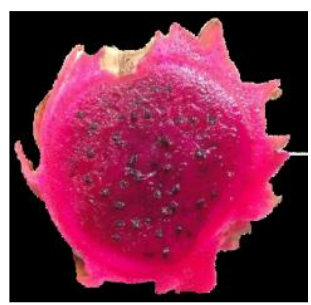

G16 accession, dark pink

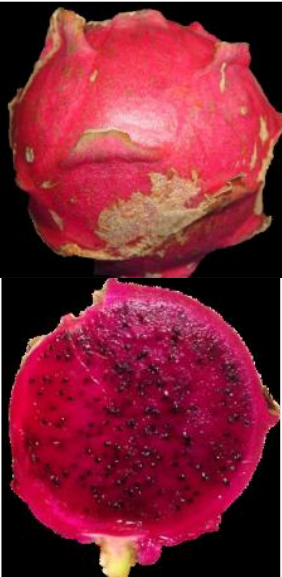

G9 accession, medium

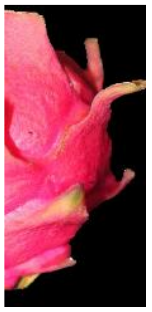

G6 accession, slightly held out

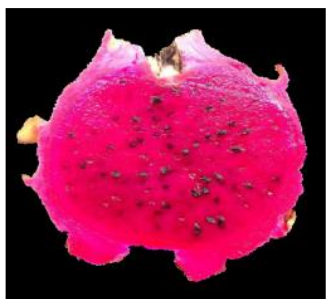

G6 accession, medium pink

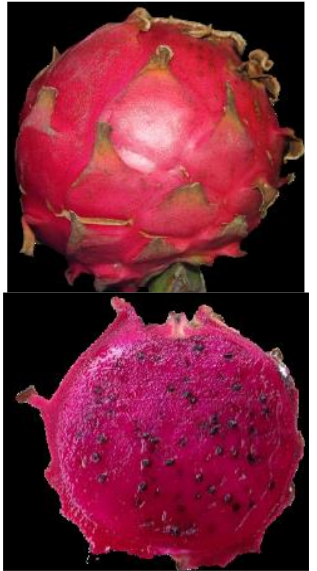

G41 accession, moderately compressed

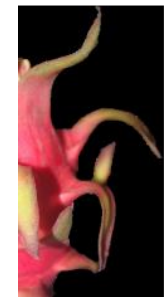

G22 accession, strongly held out

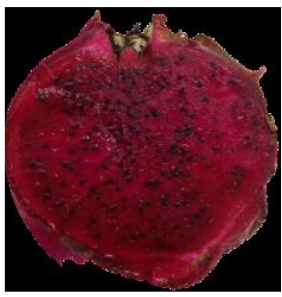

G36 accession, dark red

Figure 3. Fruit morphological characters showing phenotypic diversity

Table 3. Flower characteristics of 56 accessions of dragon fruit plants showing broad phenotype diversity in Dairi Sub-district, North Sumatra Province, Indonesia

\begin{tabular}{ccccccc}
\hline \multirow{2}{*}{ Value } & \multicolumn{5}{c}{ Morphological of flower characteristic } \\
\cline { 2 - 7 } & $\begin{array}{c}\text { Length of } \\
\text { pericarpel }(\mathbf{c m})\end{array}$ & $\begin{array}{c}\text { Width of } \\
\text { pericarpel }(\mathbf{c m})\end{array}$ & $\begin{array}{c}\text { Lenght of stigma } \\
(\mathbf{c m})\end{array}$ & $\begin{array}{c}\text { Number of stigma } \\
\text { lobes (unit) }\end{array}$ & $\begin{array}{c}\text { Length of the top } \\
\text { flower (cm) }\end{array}$ & $\begin{array}{c}\text { Length of } \\
\text { pericarpel }(\mathbf{c m})\end{array}$ \\
\hline $\bar{X}$ & 15.86 & 4.07 & 15.3 & 26.71 & 16.29 & 15.86 \\
$\sigma^{2} \mathrm{p}$ & 5.81 & 0.38 & 2.16 & 5.75 & 5.57 & 5.81 \\
$\mathrm{Sd} \sigma^{2} \mathrm{p}$ & 2.41 & 0.61 & 1.47 & 2.40 & 2.36 & 2.41 \\
$2 \mathrm{Sd} \sigma^{2} \mathrm{p}$ & 4.82 & 1.22 & 2.94 & 4.79 & 4.72 & 4.82 \\
Criteria & Broad & Narrow & Narrow & Broad & Broad & Broad \\
\hline
\end{tabular}

In flower morphological characterization, there are three characters with wide phenotypic diversity, namely length of pericarpel, number of lobes, and length of top flower; and two characters with narrow phenotypic diversity, namely width of pericarpel and length of stigmas (Table 3). Whereas for fruit morphological characterization, there were three characters with wide phenotypic diversity: number of bractea, length of apex bractea, fruit weight. Five characters with narrow phenotypic diversity were fruit length, fruit width, length of base bracts, the thickness of peel, and the sweetness of the fruit (Table 4). Apart from differences in species or accessions, differences in fruit morphology can be related to changes in the physiological level of dragon fruit at various stages of fruit development (Kammapana et al. 2013). The main differences among several Hylocereus species were the size and color of the fruit and the number and form of the spines (De Dios 2005). There are several 
species of dragon fruit that were cultivated in Indonesia, they are white dragon fruit $(H$. undatus); red dragon fruit $(H$. polyrhizus); purplish-red dragon fruit $(H$. costaricensis); and yellow dragonfruit (H. megalanthus) (Andoko and Nurrasyid 2012).

\section{Phylogenetic of dragon fruits in Dairi District}

The relationship between 56 accessions of dragon fruit plants planted in Dairi District could be evaluated based on the dissimilarity value between accessions. The smaller the dissimilarity value between one variable and another, the closer the relationship between variables is (the more similar), on the contrary, the greater the dissimilarity value, the higher the dissimilarity between variables. The lowest dissimilarity value (3.790) of dragon fruit plants was accession G19 and G24, identified in Dairi planted in Sidikalang Sub-district, Sitinjo Village 2. The close relationship between G24 and G19 was indicated by the existence of six different characters (bractea position on fruit, fruit flesh color, spines length, pericarpel width, fruit width, fruit sweetness) out of the 35 observed characters. The highest dissimilarity value (12.773) was obtained in G1 accession found in Sidikalang Sub-district, Batang Beruh Village, and accession G17 found in Sidikalang Subdistrict, Sitinjo Village 2, with 19 character differences from the studied 35 characters. These 19 different characters were stem texture, bone edge shape, red-colored flower buds. flower bud shape and, flower bud color, cleavage on the lobe, length/width ratio, fruit skin color, pulp color, the main color of bractea, distance between areoles, length of thorn, length of bractea peak, skin thickness, base width bractea, fruit sweetness, fruit weight, and fruit length. Results showed dissimilarity values of other accessions in Dairi District as in Table 5.

Based on dendrogram grouping (Figure 4) there are two, three, and four groupings at 25, 20, 17 euclidean distance scales, respectively. The small euclidean distance scale indicates the studies' accessions are closely related and have more similar characters.

On 25 euclidean distance scale, the accessions we classified into two groups. The first group consisted of 55 accessions of dragon fruit plants, namely G1, G2, G3, G4, G5, G6, G7, G8, G9, G10, G11, G12, G13, G14, 15, G16, G18, G19, G20, G21, G22, G23, G24, G25, G26, G27, G28, G29, G30, G31, G32, G33, G34, G35, G36, G37, G38, G39, G40, G41, G42, G43, G44, G45, 46, G47, 48, 49, G50, G51, G52, G53, G54, G55, G56. This group is united by a special character, namely the convex edge of the stem bone. The second group consisted only of G17 accessions, which did not form groups with other accessions. A special character that separates G17 from other accessions is the flat edge of the stem bone.

On a scale of 20, there are three groupings of phylogenetic relationships. The first group consisted of 52 accessions of dragon fruit plants, namely G2, G3, G4, G5, G6, G7, G8, G9, G10, G11, G12, G13, G14, 15, G18, G19, G20, G21, G22, G23, G24, G25, G26, G27, G28, G29, G30, G31, G32, G33, G34, G35, G36, G37, G38, G39, G40, G41, G42, G43, G44, G45, G46, G47, 48, 49, G50, G51, G52, G53, G54, G56. This group is connected by a special character that is an edge of the stem bone which is convex and the yellowish-green flower buds. The second group consisted of G1, G16, and G55 accession. This group is related to special red flower buds. The third group consisted of a single accession that is G17 with a special character that is a flat edge of the stem bone.

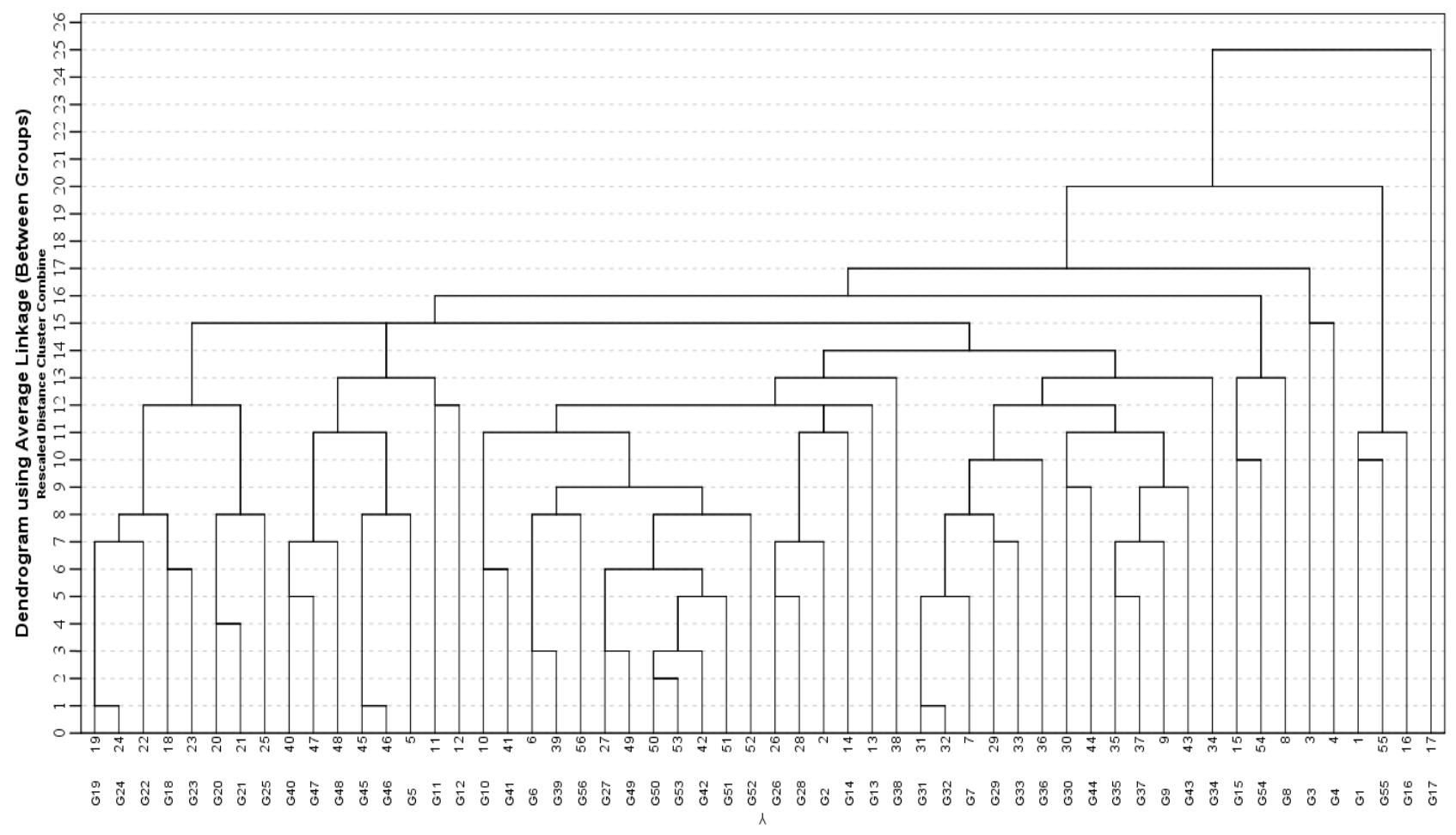

Figure 4. Dendrogram grouping based on quantitative and qualitative characters of dragon fruit accession obtained from Dairi District, North Sumatra Province, Indonesia 
Table 5. The relationship of dragon fruit accessions in Dairi District, North Sumatra, based dissimilarity matrix

\begin{tabular}{cccc}
\hline Number & \multicolumn{2}{c}{ Phylogenetic } & Dissimilarity \\
\hline 1 & G19 & G24 & 3.790 \\
2 & G45 & G46 & 3.881 \\
3 & G31 & G32 & 4.040 \\
4 & G41 & G50 & 4.727 \\
5 & G20 & G21 & 4.831 \\
6 & G26 & G28 & 4.961 \\
7 & G53 & G7 & 4.964 \\
8 & G6 & G56 & 5.049 \\
9 & G35 & G37 & 5.063 \\
10 & G27 & G51 & 5.198 \\
11 & G18 & G23 & 5.226 \\
12 & G2 & G26 & 5.238 \\
13 & G10 & G49 & 5.332 \\
14 & G39 & G42 & 5.466 \\
15 & G5 & G6 & 5.528 \\
16 & G47 & G48 & 5.532 \\
17 & G33 & G36 & 5.834 \\
18 & G30 & G40 & 5.876 \\
19 & G27 & G38 & 6.997 \\
20 & G38 & G50 & 7.003 \\
21 & G39 & G52 & 7.018 \\
22 & G37 & G19 & 7.035 \\
23 & G25 & G52 & 7.036 \\
24 & G54 & G45 & 10.162 \\
25 & G18 & G16 & 10.250 \\
26 & G8 & G34 & 10.401 \\
27 & G16 & G22 & 10.495 \\
28 & G17 & G1 & 12.773 \\
\hline & & & \\
\hline
\end{tabular}

On a scale of 17 , four distinct groups were observed. The first group consisted of 50 accessions of plants G2, G4, G5, G6, G7, G8, G9, G10, G11, G12, G13, G15, G18, G19, G20, G21, G22, G23, G24, G25, G26, G27, G28, G29, G30, G31, G32, G33, G34, G35, G36, G37, G38, G39, G40, G41, G42, G43, G44, G45, 46, G47, 48, 49, G50, G51, G52, G53, G54, G56. The second group consisted of $\mathrm{G} 3$ and G14 which are related to 11 similar characters The third group consisted of G1, G16, and G55. The fourth group is only G17 which segregates itself.

Results obtained showed that the relationship between the dragon fruit accessions understudied could be categorized as relatively close. Cahyarini et al. (2004) stated that two or more accessions/accessions can be said to be similar if the similarity distance or similarity level is not less than 0.60 or $60 \%$. Hence it can be said that the fifty-six accessions observed had close relationships with each other. According to the dragon fruit plant owners, the dragon fruit plants are reproduced by stem cuttings and thus have a high level of genetic similarity. Dragon fruit plants are found scattered in some areas, there is the possibility that they come from a single genetic source with different genetic types and then dispersed to various places with the help of humans. This is also consistent with research conducted by Rahmawati and Mahajoeno (2009) and Grimaldo-Juarez et al. (2007) that purplish-red and red dragon fruit were in the same group, hence they had a close relationship with each other. Although the G17 accession is in a separate group because it is the shape of the flat bone edges. Morillo et al. (2016) stated that several morphological characteristics can be described to distinguish various types of dragon fruit species. One of the most important characteristics of Hylocereus to distinguish it is the morphology of the stem (Grimaldo-Juarez et al. 2007).

Studies in other countries have found high variation in characteristics of agronomic importance, even within the same species of $H$. undatus which is considered favorable for future breeding studies (Tel-zur et al. 2011). Several accessions of dragon fruit plants have distinctive morphological characters and can be used as a good material source breeding programs or as propagation materials due to several characters, such as high total soluble sugar characters as found in G51, G53 G1, G8, G12, G27 (19.4-20.0 Brix), the large fruit size of G36, the thin thickness of fruit peel in G17 and G25. Such characteristics are attractions for dragon fruit marketing.

In conclusion, stem, flower, and fruit morphological characters could be used for the characterization of dragon fruit variants in Dairy District, Indonesia. Characteristics of pink to red flesh and red fruit skins indicate that the dragon fruit plant that farmers in Dairi District widely cultivate is a species of $H$. polyrhizus. Based on the analysis of phenotypic diversity, quantitative characters with broad criteria, namely stem length for stem morphology; the length of pericarpel, number of lobes, length of top flower for flower morphology; and number of bractea, length of apex bractea, fruit weight for fruit morphology. Based on phenotypic diversity, most of the accessions planted in this area are closely related.

\section{REFERENCES}

Andoko A, Nurrasyid H. 2012. Five Successful Moves to Produce Prime Quality Dragon Fruit. PT AgroMedia Pustaka, Jakarta. [Indonesian]

Cahyarini RD, Yunus A, Purwanto E. 2004. Identification of the genetic diversity of some local varieties of soybean in Java based on isozyme analysis. Agrosains 6: 79-83. [Indonesian]

Castillo R, Livera M, Márquez GJ. 2005. Caracterización morfológica y compatibilidad sexual de cinco genotipos de pitahaya (Hylocereus undatus). Agrociencia 39: 183-194.

De Dios HC. 2005. A new subspecies of Hylocereus undatus (Cactaceae) from Southeastern México. Haseltonia 11: 11-17. DOI: 10.2985/1070-0048(2005)11[11:ANSOHU]2.0.CO;2

Grimaldo-Juarez O, Terrazas T, Garcia-Velasquez A, Cruz-Villagas M, Ponce-Medina JF. 2007. Morphometric analysis of 21 pitahaya (Hylocereus undatus) genotypes. J Prof Assoc Cactus Dev 9: 99-117.

Hernandez YDO, Salazar JAC. 2012. Pitahaya (Hylocereus spp.): A short review. Comunicata Scientiae 3: 220-237.

Kammapana L, Buanong M, Techavuthiporn C, Jitareerat P, Wongs-Aree C, Yamauchi N, Srilaong V. 2013. SEM studies on the morphology of 'white pulp' dragon fruit. Acta Hortic 989: 85-90. DOI: 10.17660/ActaHortic.2013.989.8

Korotkova N, Borsch T and Arias S. 2017. A phylogenetic framework for the Hylocereeae (Cactaceae) and implications for the circumscription of the genera. Phytotaxa 327 (1): 1-46. DOI: 10.11646/phytotaxa.327.1.1

Kristanto D. 2008. Cultivating Dragon Fruit in Pots and in Gardens. Penebar Swadaya, Jakarta. [Indonesian]

Le Bellec F, Vaillant F, Imbert E. 2006. Pitahaya (Hylocereus spp.), a new fruit crop, a market with a future. Fruits 61: 237-250. DOI: 10.1051/fruits:2006021 
Mansyah E, Baihaki A, Setiamihardja R, Darsa JS, Sobir, Poerwanto R. 2003. Phenotypic variability of mangosteen in several production centers in Java. J Hortic 13: 147-156. [Indonesian]

Mejia HA, Ruiz SBM, Montoya CA, Sequeda CR. 2013. In situ morphological characterization of Hylocereus spp. (Fam. Cactaceae) genotypes from Antioquia and Córdoba (Colombia). Rev Fac Nal Agric Medellin 66: 6845-6854.

Mongi, CE. 2015. Usage Two-Step Cluster Analysis for Mixed Data JDC, Vol 4: 1. Sam Ratulangi University, Manado.

Morillo AC, Tovar YP, Morillo Y. 2016. Morphological characterization of Selenicereus megalanthus (K. Schum. ex Vaupel) moran in the province of Lengupa. Ciencia en Desarrollo 7: 23-33. DOI: 10.19053/01217488.v7.n2.2016.4072

Purba R. 2012. 21 Popular Tabulamplot Types. Agromedia, Jakarta [Indonesian]

Rahmawati B, Mahadjoeno E. 2009. Variation of morphology, isozymic, and vitamin $\mathrm{C}$ content of dragon fruit varieties. Nus Biosci 1 (3): 133137. DOI: $10.13057 /$ nusbiosci/n010305

Santoso PJ. 2013. Cultivation of organic dragon fruit in the yard, based on the experience of farmers in Malang District. Iptek Hortikultura 9: 2631. [Indonesian]
Setyowati A. 2008. Morphological and Cytological Analysis of Yellow Skin Dragon Fruit Plants (Selenecerus megalanthus). Thesis. Universitas Sebelas Maret, Surakarta. [Indnesian]

Sudjana. 2008. Statistical Method. PT Tarsito, Bandung. [Indonesian]

Steel RGD, Torrie JH, Dicke DA. 1997. Principles and Procedures of Statistics: A Biometrical Approach. 3rd Edition, McGraw Hill, Inc. Book Co., New York, Winarsih S. 2010. Recognizing and Cultivating Dragon Fruit. Aneka Ilmu, Semarang. [Indonesian]

Sudarjat, Leovika A, Suminar E, Isnaniawardhani V, Qanit MAH, Fauzi AA, Mubarok S. 2019. Morphological characterization and adaptation of four dragon fruit genotypes in Pangandaran District of Indonesia. Asian J Plant Sci 18: 21-25. DOI: 10.3923/ajps.2019.21.25

Tel-Zur N, Mizrahi Y, Cisneros A, Mouyal J, Schneider B, Doyle JJ. 2011. Phenotypic and genomic characterización of vine cactus collection (Cactaceae). Genet Resour Crop Evol 58: 1075-1085. DOI: 10.1007/s10722-010-9643-8

Tran DH, Yen CR. 2014. Morphological characteristics and pollination requirement in red pitaya (Hylocereus spp.). Int J Agric Biosys Eng 8: 268-272. 